\title{
ESTRATÉGIAS DIDÁTICAS UTILIZADAS NO ENSINO DE QUÍMICA: CONCEPÇÕES DE PROFESSORES E ESTUDANTES
}

\section{DIDACTIC STRATEGIES USED IN CHEMISTRY EDUCATION: TEACHER AND STUDENT CONCEPTIONS}

Joyce Francielle dos Santos Araújoㅜㄹ Wellington de Souza Ferreira ${ }^{2}$; Cíntia de Abreu Arruda ${ }^{3}$; Kilma da Silva Lima Viana ${ }^{4}$;

\section{INTRODUÇÃO}

O Ensino de Química nas escolas se restringe,na maioria das vezes, à abordagem tradicional, onde o papel do professor é transmitir conhecimentos e os estudantes são meros receptores, além da utilização de regras, fórmulas e nomenclaturas e na maioria das vezes não há contextualização do conteúdo com o cotidiano do aluno (ARRUDA et al, 2016).

Segundo Sasseron e Carvalho (2011), é relatado que inúmeras investigações realizadas na área da didática das ciências (Química, Física e Biologia) têm evidenciado um baixo rendimento no estudo dessas disciplinas, além de identificado uma acentuada aversão dos estudantes a essas áreas de estudo.

Diante desse contexto, a importância desta pesquisa está em considerar que a busca por novas metodologias ou estratégias no ensino de Química pode motivar o interesse do aluno e facilitar no processo de aprendizagem desta disciplina.

Portanto, não existe uma receita de bolo para isso, nessa perspectiva, cada professor pode inovar buscando técnicas pedagógicas capazes de atender às necessidades dos estudantes, identificando, analisando cada turma ou grupo de estudantes que atua com a disciplina de Química, observando e considerando a diversidade na sala de aula uma vez que há aqueles com mais ou menos dificuldades de aprendizado.

Sendo assim nos perguntamos: Qual a visão de estudantes e professores acerca das estratégias didáticas utilizadas nas aulas de ensino de Química? Logo, para responder a esse questionamento a nossa pesquisa teve como objetivo investigar as concepções de estudantes e professores acerca das principais estratégias didáticas utilizadas em aulas de Química, através da utilização de dois questionários, com perguntas nessa temática.

\footnotetext{
${ }^{1}$ Licenciatura em Química, IFPE - Campus Vitória de Santo Antão, joycefranaraujo@gmail.com

${ }^{2}$ Licenciatura em Química, IFPE - Campus Vitória de Santo Antão, souza.wellington@gmail.com

3 Pós-graduação em Educação, Ensino de Ciências e Matemática, UFPE - CAA, cintiaarruda@ outlook.com

${ }^{4}$ Doutora em Ensino das Ciências, IFPE, kilma.viana@vitoria.ifpe.edu.br
} 


\section{FUNDAMENTAÇÃO TEÓRICA}

SegundoValente (2009), a Didática Geral é uma ciência teórica - prática que:

[...] pesquisa, experimenta e sugere formas de comportamentos a serem adotados no processo de ensino aprendizagem, resultando na eficiência e eficácia da ação educativa, sendo ferramenta cotidiana do professor e, como tal, está em contínua evolução, portanto o professor deve se aperfeiçoar e atualizar seu conhecimento sobre novas técnicas que possam ser utilizadas em sala de aula.

Porém, relacionando com a didática no Ensino de Química, sabemos que há um fracasso no processo de aprendizagem dessa disciplina. Neste sentido, Lima e Leite (2015), destaca que a realidade, mostra que o Ensino de Química não é de baixo nível, apenas não acompanha a evolução que ocorre nos tempos atuais. Em termos práticos, sua metodologia se efetua de forma exclusivamente verbalista, na qual a aprendizagem é entendida somente como um processo de acumulação de conhecimentos.

Dentre as diversas estratégias didáticas propostas para reverter este quadro, duas merecem destaque: atividades experimentais e softwares educacionais. Um ponto em comum destas duas metodologias está nos resultados positivos que rotineiramente são apresentados na literatura especializada.

Referentes as atividades experimentais no Ensino de Química, Schwalm e Oaigen (2009), consideram que:

[...] o uso de atividades experimentais pode vir a ser o ponto de partida para a compreensão de conceitos e sua relação com as ideias discutidas em sala de aula com os estudantes, estabelecendo relações entre a teoria e a prática e, ao mesmo tempo criando possibilidades para que o estudante expresse suas dúvidas, permitindo assim que ocorra construção do conhecimento.

Já referentes ao uso de softwares educacionais, Dallacosta et al. (1998) constataram que:

[...] os computadores têm revolucionado a educação em Química. Segundo estes autores, os recursos computacionais atraem e motivam os estudantes, aumentam a capacidade de compreensão, favorecem a visualização de conteúdos abstratos e de reações químicas potencialmente perigosas e seu uso pode ser estendido ao laboratório.

Portanto, para que o processo de ensino-aprendizagem seja relevante para o aluno, é imprescindível que o professor alie a contextualização do conteúdo a ferramentas tecnológicas e estratégias didáticas como a experimentação, que facilitam a criação de situações problemas que estimulam a construção do conhecimento, e o desenvolvimento do senso crítico e reflexivo (GUIMARÃES, 2009).

\section{METODOLOGIA}

Essa pesquisa apresentou uma abordagem qualitativa, com o objetivo de investigar as concepções de estudantes e professores acerca das principais estratégias didáticas utilizadas em 
aulas de Química.

Foi desenvolvida na instituição de ensino Ginásio de Limoeiro Artur Correia de Oliveira (Instituição 1), localizada na cidadedeLimoeiro, e na escola Amélia Coelho (Instituição 2), localizada na cidade de Vitória de Santo Antão,ambasno estado de Pernambuco.Os sujeitos que participaram da pesquisa foram, trinta e quatro $(n=34)$ estudantes da turma "A" e trinta e seis $(\mathrm{n}=36)$ da turma " $\mathrm{B}$ " do $3^{\circ}$ ano do Ensino Médio da (Instituição 1), e na (Instituição 2), trinta e um $(n=31)$ estudantes da turma " $A$ " e vinte e cinco $(n=25)$ da turma " $B$ " do $3^{a}$ ano do Ensino Médio, e dois (n=2) professores que lecionam Química, da Instituição 1 e 2.

Para coleta de dados, foram utilizados dois questionários, um com os estudantes e outro com os professores,com o objetivo de conhecer e analisar o uso das principais estratégicas didáticas utilizadas em aulas de Química.

\section{Questionário aplicado aos estudantes:}

(Q1)O que você acha da disciplina de Química?

(Q2)A forma como o seu professor ensina lhe motiva a aprender Química? Você considera as aulas atrativas? Porquê?

(Q3)Seu professor de Química relaciona os conteúdos com o seu cotidiano?

(Q4)Nas aulas de Química, o seu professor utiliza quais recursos didáticos abaixo:

( ) Quadro; ( ) Livro didático; ( ) Experimento; ( ) Jogos didáticos; ( ) Data show.

(Q5)Para você é importante ter aulas de Química experimentais? Por quê?

(Q6)De que forma o Ensino de Química poderia ser mais fácil ou compreensível para você?

\section{Questionário aplicado aos professores:}

(Q1)Você é formado em Licenciatura em Química? Se não, qual a sua formação?

(Q2)Quais os recursos didáticos você utiliza em suas aulas de Química?

(Q3)Qual a sua opinião acerca do uso de experimentos para o ensino de Química?

\section{RESULTADOS E DISCUSSÕES}

\section{Discussão das análises dos questionários dos estudantes}

De acordo com os resultados do questionário aplicado aos estudantes de ambas as escolas observamos que referente a $(\mathrm{Q} 1)$, setenta $(\mathrm{n}=75)$ estudantes, responderam que a disciplina de Química é difícil, complicada, ruim e desnecessária e cinquenta e um $(\mathrm{n}=51)$ responderam que a disciplina de Química é legal, interessante, atrativa e muito importante.

Baseado nas respostas da (Q2 e Q3) analisamos que os estudantes apresentam uma grande dificuldade no aprendizado em Química, pois mais de $80 \%$ dos estudantes, ou seja, sessenta e dois $(n=62)$ da Instituição 1 e quarenta $(n=40)$ da Instituição 2, relataram que o seu professor de Química na maioria das vezes não faz relação dos conteúdos com o seu cotidiano, 
o que consequentemente não lhe motiva a aprender Química, pois o conhecimento precisa ter sentido e significado.

Com base nisso, destacamos que essa grande dificuldade para a aprendizagem em Química, está relacionado com as estratégias didática utilizada pelos professores em suas aulas, visto que, os docentes utilizam uma forma muito técnica no processo de ensino, pois cobra que o aluno decore conceitos e fórmulas desta disciplina, esquecendo-se de contextualizar e trazer aulas práticas com exemplos de ações cotidianas como é apresentado na (Q4). Observa-se a partir das respostas que a utilização do quadro é o recurso didático mais utilizado, como podemos ver no gráfico abaixo:

Figura1: Gráfico referente as respostas da (Q4). Fonte: Própria.

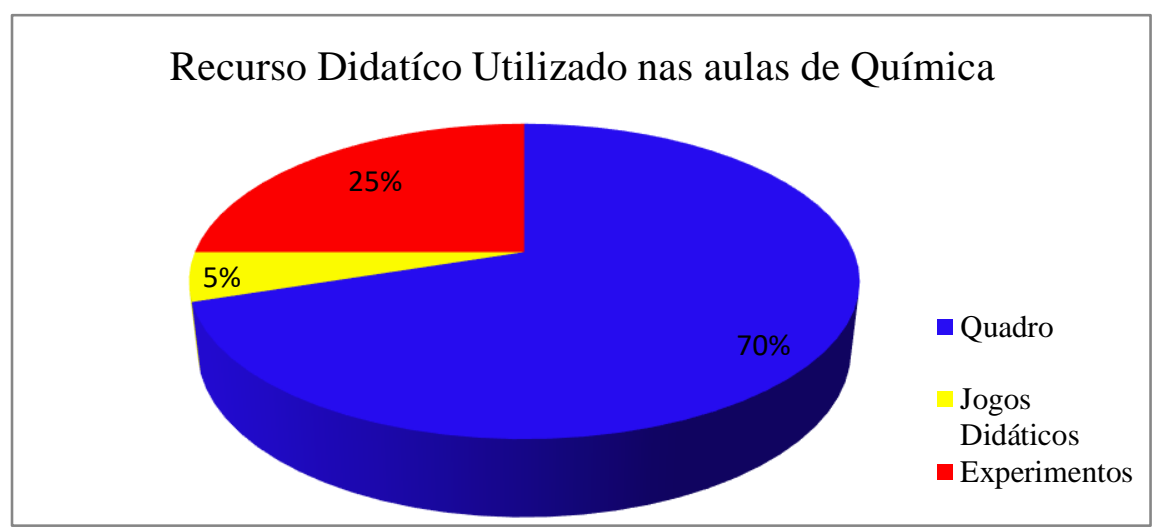

Nesse sentido, a utilização constante de um único recurso didático, traz ao discente uma sensação monótona, contribuindo para o desinteresse pela matéria.Mas, para uma aprendizagem significativa, os recursos didáticos devem ter um caráter motivador para o aluno.

Já relacionado a (Q5), cento e doze $(n=112)$ dos estudantes questionados, consideram importantes as aulas experimentais no ensino de Química, como podemos ver em algumas falas abaixo:

"É importante, pois na minha opinião aprende melhor praticando."

"Sim. Porque são coisas novas, aula diferente e isso incentiva mais os alunos a estudarem."

"É importante sim, porque vários experimentos são muito importantes no nosso dia-adia onde temos que entender."

"Sim, é muito mais atrativo e interessante."

Também foi possível analisar pelas respostas dos estudantes na (Q6), que ter apenas aulas teóricas, não é o suficiente para o aprendizado, sentindo assim, uma carência em aulas dinâmicas e de laboratório. Logo, as realizações de aulas práticas experimentais são muito importantes, pois possibilita ao aluno uma melhor fixação dos conteúdos trabalhados em sala de aula, torna a aula mais dinâmica e também ocasiona uma maior interação entre professor e 
aluno.

\section{Discussão das análises dos questionários dos professores}

Relacionado as respostas dos questionários aplicados aos professores, foi analisado na (Q1) que a professora da Instituição 1, é formada em Ciências com habilitação em Biologia e a professora da Instituição 2 é licenciada em Química.

Já, relacionado a $(\mathrm{Q} 2)$ sobre os recursos didáticos utilizados por eles em suas aulas de Química, foi abordado os seguintes: projetor, fichas de estudos e de exercícios, o uso de livros didáticos, montagem e execução de jogos, maquetes, seminários e aulas de experimentações.

Mas, foi destacado que o uso da experimentação e de jogos didáticos são raramente aplicados, em geral, as aulas são padronizadas, na utilização do quadro e livros didáticos, o que pode ser uma das causas para a desmotivação dos estudantes para a aprendizagem desta área do conhecimento que é a Química, pois ter aulas "repetitivas" acarreta essa carência no aprender e no interagir.

Ambos os professores relataram na (Q3), que a realização de aulas experimentais facilita a associação teoria e prática, desperta a curiosidade dos discentes, percebendo-se um maior desenvolvimento dos estudantes como também maior interação com a disciplina. Mas, lamentavelmente não utilizam muito essa forma didática por carências em materiais, quantitativo elevado de alunos, dificultando o domínio da turma, pois o ambiente exige muito cuidado, e até mesmo pela falta de tempo e a grande demanda de conteúdos no bimestre.

Baseado nisso, Marandino, Selles e Ferreira (2009) apud Wyzykowski et al (2011),relatam que, muitos professores gostariam de ampliar as atividades experimentais com os alunos, mas são barrados pelo tempo curricular, por limitações oriundas dos processos de formação docente, pela ausência de ordem estrutural destinado à experimentação e à falta de controle sobre um grande número de alunos dentro de um laboratório.

\section{CONCLUSÕES}

Diante do exposto, podemos concluir que a grande dificuldade para a aprendizagem em Química, está relacionado com as estratégias didática utilizada pelos professores em suas aulas, pois tanto na visão dos estudantes e dos professores foi relatado que as aulas são tradicionais/padronizadas, com foco na utilização do quadro e livros didáticos, o que ocasiona em aulas monótonas e desinteressantes, e corrobora para a desmotivação dos estudantes para a aprendizagem desta área do conhecimento.

Mas, relacionado as atividades experimentais para o ensino de Química ambos também 
relataram que este recurso didático é de suma importância, pois facilita a associação teoria e prática e desperta a curiosidade e o interesse dos estudantes para a Química. Mas, os professores mencionaram não utilizar com tanta frequência, por carência em materiais, quantitativo elevado de alunos, e até mesmo pela falta de tempo, pois há uma grande demanda de conteúdos para serem cumpridas.

Logo, os governos federal e estadual precisam oferecer para o ensino público um ambiente melhor e mais qualificado para o desenvolvimento do ensino de Química, pois o conhecimento desta área é de grande importância para a nossa vida.

\section{REFERÊNCIAS}

ARRUDA, C. A.; SANTOS, M. T. S.; AMARAL, E. V. F.; VIANA, K. S. L. Avaliação da Aprendizagem no Ensino de Cinética Química. 2016. In: I SimposioLatinoamericano em Formación de Profesores: Tecnología y Educación, 2016, Playa Ancha - Valparaíso. Anais do I SimposioLatinoamericano em Formación de Profesores: Tecnología y Educación, 2016.

DALLACOSTA, A.; FERNANDES, A. M. R.; BASTOS, R. C. Desenvolvimento de um software educacional para o ensino de química relativo à tabela periódica. In: IV Congresso Da Rede Iberoamericana de Informática Educativa (RIBIE), 1998, Brasília - DF. Anais do IV Congresso Da Rede Iberoamericana de Informática Educativa, 1998.

GUIMARÃES, C. C. Experimentação no Ensino de Química: Caminhos e Descaminhos Rumo à aprendizagem significativa. Química Nova na Escola, São Paulo - SP, v.31, n.3, p. 198-202, 2009.

LIMA, J. O. G.; LEITE, L. R. Novas Estratégias Didáticas para um Ensino de Química mais Significativo. In: Isabel Maria Sabino de Farias; Maria do Socorro Lucena Lima; Maria Marina Dias Cavalcante; José Álbio Moreira de Sales. (Org.). Didática e Prática de Ensino na relação com a Formação de Professores. 1ed.Fortaleza: EdUECE, 2015, v. 4, p. 1-5, 2015.

SASSERON, L. H.; CARVALHO, A. M. P. Alfabetização científica: uma revisão bibliográfica.Investigações em Ensino de Ciências, v. 16, n. 1, p. 59-77, 2011.

SCHWALM, M. C. A.; OAIGEN, R. Objetivos para o uso da experimentação no ensino de Química: a visão de um grupo de licenciandos. In: VII Encontro Nacional de Educação em Ciências (VII ENPEC), 2009, Florianópolis - SC. Anais do VII Encontro Nacional de Educação em Ciências, 2009.

VALENTE, N. DIDÁTICA: ferramenta cotidiana do professor. Disponível em:〈https://www.webartigos.com/artigos/didatica-ferramenta-cotidiana-do-professor/16960> Acesso em: 25 de setembro de 2018.

WYZYKOWSKI, T. et al. A Experimentação no Ensino Fundamental de Ciências: A Reflexão em Contexto Formativo.In:VIII Encontro Nacional de Pesquisa em Educação em Ciências, 2011, Campinas - SP. Anais do VIII Encontro Nacional de Pesquisa em Educação em Ciências, 2011. 